\title{
Lecanorchis japonica var. insularis (Orchidaceae: Vanilloideae), a new variety from Jejudo Island, Korea
}

\author{
Seon-Won SEO, Mi-Sook CHUNG ${ }^{1}$, Young-Soon CHUNG ${ }^{1}$, \\ Chae Eun LIM² and Sang-Hun $\mathrm{OH}^{*}$ \\ Department of Biology, Daejeon University, Daejeon 34520, Korea \\ ${ }^{1}$ Daejeon University (Citizen Researcher), Jeju 63582, Korea \\ ${ }^{2}$ Plant Resources Division, National Institute of Biological Resources, Incheon 22689, Korea \\ (Received 27 November 2020; Revised 22 December 2020; Accepted 28 December 2020)
}

\begin{abstract}
A new variety, Lecanorchis japonica var. insularis (Orchidaceae: Vanilloideae), a mycoheterotrophic orchid from Jejudo Island, Korea, is described and illustrated. It usually grows with L. japonica var. japonica, $L$. japonica var. hokurikuensis and L. kiusiana in evergreen forests. The newly described variety is distinguished from L. japonica vars. japonica, hokurikuensis, and kiiensis by having fully opened, larger flowers and an obtuse labellum apex.
\end{abstract}

Keywords: morphology, Lecanorchis, new taxon, orchid, taxonomy

Lecanorchis Bl. (Orchidaceae; Vanilloideae; Vanilleae) consists of approximately 30 species of mycoheterotrophic orchids that are widely distributed in tropical and subtropical Southeast Asia, the Pacific islands, and in certain warm temperate regions of eastern Asia, such as China, Taiwan, Korea and Japan (Hashimoto, 1990; Dressler, 1993; Pearce and Cribb, 1999; Pridgeon et al., 2003; Suetsugu and Fukunaga, 2016; Suetsugu et al., 2018). Lecanorchis is characterized by having leafless stems, a calyculus (i.e., a prominent cupulate structure at the base of the perianth), an elongated, slender column adnate to the labellum at the base, and polyporate pollen (Hashimoto, 1990; Dressler, 1993; Suetsugu and Fukunaga, 2016).

Two or three species with five varieties of Lecanorchis, typically in broadleaved evergreen forests, are in Korea (Lee, 2011). Lecanorchis japonica Bl., the type species of the genus, occurs on offshore islands in southern Korea and on Jejudo Island. It also occurs in southeastern China, Taiwan, and Japan. The Japanese variety, L. japonica var. hokurikuensis (Masam.) T. Hashim., has been recorded in Korea (Lee, 2011). It can be distinguished from $L$. japonica var. japonica by having an incision on the column wings and muricate surface of the ovary and sepals. Another variety, L. japonica var. kiiensis (Murata)
T. Hashim. (Korean name hwang-geum-mu-yeop-ran, 황금무 엽란), previously only known from the type locality in Japan (Hashimoto, 1990), is also on Jejudo. Variety kiiensis is distinguished by having bright yellow flowers. Lecanorchis kiusiana Tuyama var. kiusiana, characterized by an erect ovary and pedicel and labellum margins with papillae (Hashimoto, 1990; Lee, 2011) and L. kiusiana var. suginoana (Tuyama) T. Hashim., distinguished from var. kiusiana by having yellow hairs on the labellum, are also on Jejudo. Some recent authors recognized the latter as a distinct species, L. suginoana (Tuyama) Seriz. (Yukawa et al., 2015).

The taxonomic difficulties associated with Lecanorchis stem from the mycoheterotrophic habit, lack of leaves, short flowering period and limited distribution, often resulting in underestimations of species diversity (Suetsugu et al., 2018). During our fieldwork on Korean Orchidaceae, we found an unidentifiable population of a form of Lecanorchis growing with L. japonica and L. kiusiana on Jejudo Island. After further fieldwork and an examination of the specimens, we concluded that these plants represented a new variety of L.japonica. Here, we provide a description, illustration, and a comparison of the diagnostic characteristics with its close relatives.

\footnotetext{
*Author for correspondence: soh42@dju.kr
} 


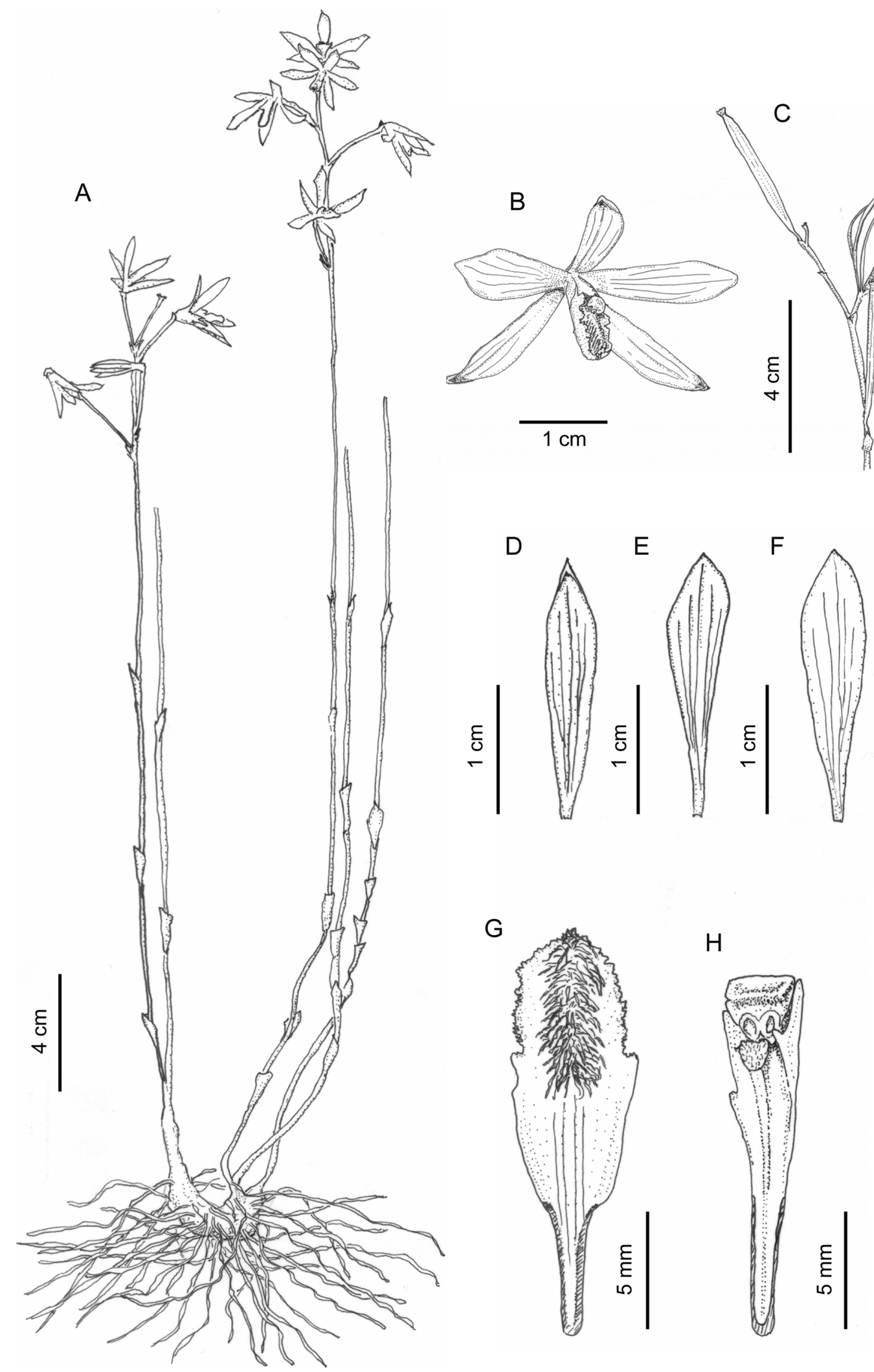

Fig. 1. Lecanorchis japonica var. insularis S.-W. Seo, M.-S. Jung, Y.-S. Jung \& S.-H. Oh. A. Habit. B. Flower, front view. C. Fruits; one of which is dehiscent. D. Dorsal sepal, abaxial view. E. Lateral sepal. F. Petal. G. Labellum, abaxial view after flattening distal part and disconnecting column at base. H. Column. Drawn from the holotype by Sang-Hun Oh. 


\section{Materials and Methods}

Morphological data were obtained from liquid-preserved specimens in FAA collected during fieldwork from 2016 to 2020 and herbarium specimens deposited in KB and TUT (acronyms according to Thiers, 2018). Measurements, colors, and shapes in regard to the descriptions of the flowers were based on the liquid-preserved collection and photographs taken during the fieldwork; characteristics of the other parts of the plants, such as the root, stem, and fruits, are from herbarium specimens. The morphology of closely related species and varieties not available in the herbaria were derived from the literature (Hashimoto, 1990; Lee, 2011). The morphological characters of the flowers of the new variety, var. insularis, were observed under an Optinity stereomicroscope.

\section{Taxonomic Treatment}

Lecanorchis japonica Bl. var. insularis S.-W. Seo, M.-S. Jung, Y.-S. Jung \& S.-H. Oh, var. nov. (Fig. 1).-TYPE: KOREA. Jeju-do, Seogwipo-si, elev. 450 m, 22 Jun 2020, $S$ $W$. Seo 8228 (holotype: KB!, dried specimen and liquidpreserved material in a bottle, with the same label).

Korean name: young-ju-mu-yeop-nan (영주무엽란).

Similar to Lecanorchis japonica vars. hokurikuensis and kiiensis but differing by fully opened, larger flowers and obtuse labellum apex; differing from L. japonica var. japonica by having fully opened, larger flowers, obtuse labellum apex, and incised column wings.

Herbs, terrestrial, 25-50 cm tall. Roots horizontally elongate, wavy, more than $10 \mathrm{~cm}$ long. Rhizome horizontal at base, with numerous roots, gradually ascending or erect; ascending portion 2-9 cm long, branched, without roots; sheaths ovate-lanceolate, $0.6-1.3 \mathrm{~cm} \times 5-7 \mathrm{~mm}$, margin ciliate, both surfaces glabrous. Stem erect, slender, above-ground portion unbranched, with 4-6 sheaths, light green or yellowish brown at anthesis, black and hardened when fruiting. Sheaths below middle portion of stem sessile, alternate, lanceolate to oblanceolate, base clasping stem, $1.1-1.2 \mathrm{~cm}$ long. Inflorescence terminal, raceme, loosely 4- to 6-flowered; floral bracts appressed to ovary, lanceolate, 4-5 × 3-4 mm, apex acute, glabrous. Flowers resupinate, bisexual, fully open, horizontally facing, yellowish brown except labellum; pedicel and ovary diverging, straight, cylindrical, $1.8-4 \mathrm{~cm}$ long, apex with a calyculus surrounding the flower; calyculus cupulate, ca. $1 \mathrm{~mm}$ tall, margin irregularly denticulate; sepals 3 , free, subequal, apex cymbiform, acute, both surfaces glabrous; dorsal sepal 1, oblanceolate, $1.6-1.8 \mathrm{~cm} \times 3.6-3.7 \mathrm{~mm}$; lateral sepals 2 , oblanceolate, weakly oblique, $1.6-1.7 \mathrm{~cm} \times 3.4 \mathrm{~mm}$; petals oblanceolate, spreading, $1.7-1.8 \mathrm{~cm} \times 3.7 \mathrm{~mm}$, glabrous, apex obtuse; labellum light purple, base adnate to column to form a tube; tube ca. $5 \mathrm{~mm}$ long; distal free part obovate, 1$2.5 \mathrm{~cm} \times 3-7 \mathrm{~mm}$ when spread out, weakly 3 -lobed, densely pubescent with yellow villous hairs, covering $7 \times 2 \mathrm{~mm}$ of distal part of labellum; midlobe 3-4 mm long, apex obtuse, margin irregularly erose-undulate; lateral lobes obscure, margin entire; column 11-13 mm long, with apical wings, glabrous; wings with an incision; anther cap white, flat or slightly depressed, ca. $2 \mathrm{~mm}$ wide, dorsally fused with column; pollinia 2; stigma obdeltoid, ca. $1 \mathrm{~mm}$ wide, pubescent with short hairs. Fruit capsules, erect, cylindrical, 3-4 cm long, 3-locular, black, shiny.

Flowering: Late May to late June.

Distribution and habitat: Lecanorchis japonica var. insularis is distributed on the south-facing slope of Hallasan Mt. on Jejudo Island. It occurs in moist places with a litter layer in broadleaved evergreen forests dominated by Castanopsis cuspidata (Thunb.) Schottky and Camellia japonica L. (Fig. 2). Populations of L. japonica var. insularis are at several sites on Jejudo. We estimate that there are more than 2,000 individuals. Lecanorchis japonica var. insularis cooccurs with L. japonica var. japonica, L. japonica var. hokurikuensis, and L. kiusiana. Lecanorchis japonica var. insularis blooms one or two weeks earlier than other varieties of L. japonica on Jejudo.

Table 1. Comparison of selected morphological characters of the varieties of Lecanorchis japonica in Korea.

\begin{tabular}{lcccc}
\hline \multirow{2}{*}{ Character } & \multicolumn{3}{c}{ L. japonica } \\
\cline { 2 - 5 } & var. insularis & var. japonica & var. hokurikuensis & var. kiiensis \\
\hline Flower diameter $(\mathrm{cm})$ & $2.5-3.5$ & $2.0-3.0$ & $2.0-3.0$ & $2.0-3.0$ \\
Flower color & Yellowish brown & Yellowish brown & Purplish brown & Bright yellow \\
Ovary surface & Smooth & Smooth or lightly scabrous & Strongly scabrous & Smooth \\
Labellum apex & Obtuse & Truncate & Truncate & Truncate \\
Column wing margin & Incised at apex & Smooth & Incised at apex & Incised at apex \\
\hline
\end{tabular}



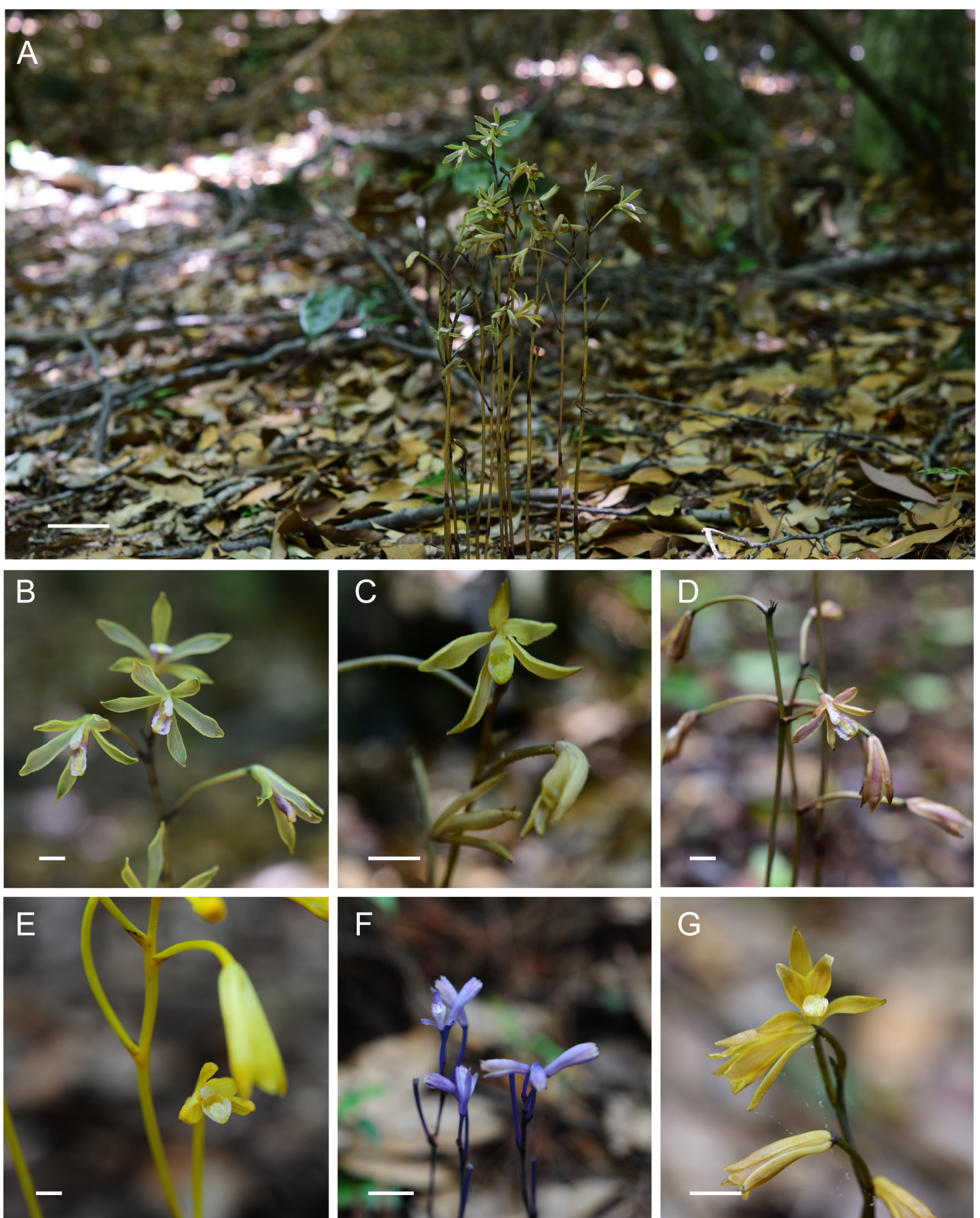

Fig. 2. Lecanorchis in Korea. A, B. L. japonica var. insularis. C. L. japonica var. japonica. D. L. japonica var. hokurikuensis. E. L. japonica var. kiiensis. F. L. kiusiana. G. L. suginoana. Scale bars: A = 4 cm, B-G $=1 \mathrm{~cm}$.

Etymology: The specific epithet, insularis, refers to the type locality of L. japonica var. insularis.

Notes: Lecanorchis japonica var. insularis is morphologically similar to L. japonica vars. hokurikuensis and kiiensis (Fig. 2) by having an incision at the apical portion of the column wing, forming an auricle (Fig. 1H). It is a diagnostic feature that has been used to distinguish the two varieties from L. japonica var. japonica and L. japonica var. tubiformis $\mathrm{T}$. 
Hashim. (Hashimoto, 1990). Lecanorchis japonica var. insularis differs from other varieties of $L$. japonica by having fully opened, larger flowers and an obtuse labellum apex.

Lecanorchis. japonica var. insularis occurs in sympatric populations of all of the Korean taxa of Lecanorchis except $L$. suginoana. Dependence on the fungal associates of mycoheterotrophic orchids may play an important role in the sympatry in Lecanorchis. The sympatric occurrence of various taxa of Lecanorchis suggests that the fungal associations of these species may not be species specific between Lecanorchis and fungi. Okayama et al. (2012) found that L. japonica and L. kiusiana have specific relationships with the fungal genus Lactarius and that no significant differences in fungal relationships between L. japonica and L. kiusiana due to geographic bias could be found in their survey. Further study is necessary to determine the relationships between the species of Lecanorchis and fungal diversity and specificity. Conservation of mycoheterotrophic orchids such as Lecanorchis require preservation of ecosystems where the ecological interactions among species maintain species diversity.

Conservation status: Based on our field study and examination of herbarium specimens, L. japonica var. insularis is restricted to Jejudo Island. Owing to the limited distribution, we consider its conservation status as Vulnerable (VU) according to IUCN criteria (IUCN 2019).

Additional specimens examined: Korea. Jeju-do: Seogwipo-si, Sanghyo-dong, Seondol, elev. 503 m, 23 Jun 2010, Kim 29862 (KB [3 sheets]); Seogwipo-si, elev. 450 m, 18 Sep 2020, Oh 20200918-01 (TUT).

\section{Key to the species and variety of Lecanorchis in Korea}

1. Plants usually more than $20 \mathrm{~cm}$ tall; flowers yellow, yellowish brown, or purplish brown; ovary and pedicel ascending or deflexed when flowers are open; margin of the distal portion of labellum without papillae.

2. Flowers bright yellow ………. L. japonica var. kiiensis

2. Flowers yellowish brown or purplish brown.

3. Column wings smooth $\cdots .$. L. japonica var. japonica

3. Column wings with an incision near apex.

4. Flowers purplish brown; ovary and pedicel spreading to reclining at anthesis; labellum apex truncate ……….. L. japonica var. hokurikuensis

4. Flowers yellowish brown; ovary and pedicel diverging and straight; labellum apex obtuse ......

L. japonica var. insularis
1. Plants $10-30 \mathrm{~cm}$ tall; flowers yellow, whitish brown, yellowish brown, or light blue; ovary and pedicel erect when flowers are open; margin of distal portion of labellum with papillae.

5. Flowers whitish brown, yellowish brown or light blue; midlobe of labellum with purple or reddish hairs .........

L. kiusiana

5. Flowers yellowish brown; midlobe of labellum with yellow hairs

L. suginoana

ORCID: Seon-Won SEO https://orcid.org/0000-0003-49248712; Mi-Sook CHUNG https://orcid.org/0000-0001-6321352x; Young-Soon CHUNG https://orcid.org/0000-0001-75162862; Chae Eun LIM https://orcid.org/0000-0002-1375-8684; Sang-Hun OH https://orcid.org/0000-0001-8778-4458

\section{Acknowledgments}

We thank Yun-Kyeong Choi, Su-Chang You, Yun-Soo Kim, and Hwa-Jung Suh for their help throughout the project. We are grateful to the curators and staff of $\mathrm{KB}$ for allowing us to examine the herbarium specimens. We thank two anonymous reviewers, and David Boufford who provided invaluable comments. This work was supported by a research grant from the National Institute of Biological Resources, the Ministry of Environment, Korea (NIBR202010101, DNA Barcode System for Korean Indigenous Plant Species).

\section{Conflict of Interest}

The authors declare that there are no conflicts of interest.

\section{Literature Cited}

Dressler, R. L. 1993. Phylogeny and Classification of the Orchid Family. Dioscorides Press, Portland, OR, 312 pp.

Hashimoto, T. 1990. A taxonomic review of the Japanese Lecanorchis (Orchidaceae). Annals of the Tsukuba Botanical Garden 9: 1-40.

IUCN. 2019. Guidelines for using the IUCN red list categories and criteria, version 14. Retrieved Jul. 30, 2020, available from https://www.iucnredlist.org/resources/redlistguidelines.

Lee, N. S. 2011. Illustrated Flora of Korean Orchids. Ewha Womans University Press, Seoul, 345 pp. (in Korean)

Okayama, M., M. Yamato, T. Yagame, and K. Iwase. 2012. Mycorrhizal diversity and specificity in Lecanorchis (Orchidaceae). Mycorhiza 22: 545-553.

Pearce, N. and P. Cribb. 1999. Notes relating to the flora of Bhu- 
tan: XXXVII. New species and records of Orchidaceae from Bhutan and India (Sikkim). Edinburgh Journal of Botany 56: 273-284.

Pridgeon, A. M., P. J. Cribb, M. W. Chase and F. N. Rasmussen. 2003. Genera Orchidacearum, Vol. 3. Oxford University Press, New York, 360 pp.

Suetsugu, K. and H. Fukunaga. 2016. Lecanorchis tabugawaensis (Orchidaceae, Vanilloideae), a new mycoheterotrophic plant from Yakushima Island, Japan. PhytoKeys 73: 125-135.

Suetsugu, K., C. Shimaoka, H. Fukunaga and S. Sawa. 2018. The taxonomic identity of three varieties of Lecanorchis nigricans
(Vanilleae, Vanilloideae, Orchidaceae) in Japan. PhytoKeys 92: $17-35$.

Thiers, B. 2018. [continuously updated] Index Herbariorum: A Global Directory of Public Herbaria and Associated Staff. Retrieved Jul. 30, 2020, available from http://sweetgum.nybg.org/science/ih/.

Yukawa, T., H. Nakayama, M. Takano, H. Matsuoka and H. Yamashita. 2015. The Handbook of Japanese Wild Orchids, Vol. 1. Warm-temperate Regions. Bun-ichi, Tokyo, 135 pp. (in Japanese) 